\title{
Contemporary Face-lift Techniques
}

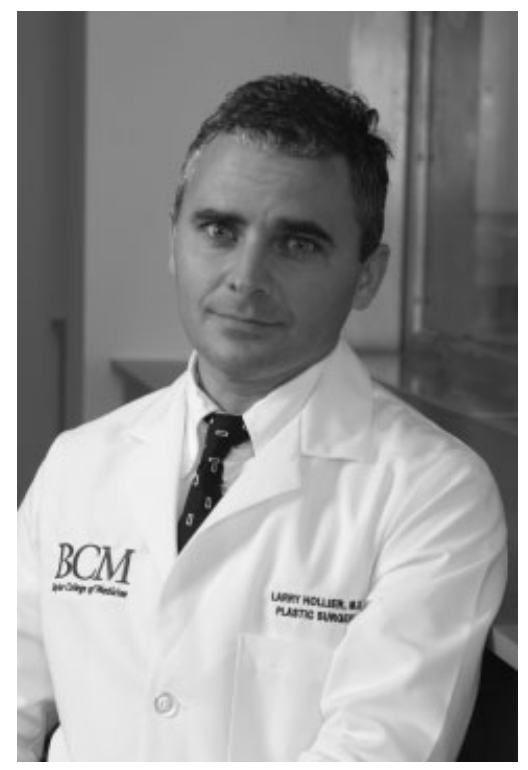

$\mathrm{I}_{\mathrm{t}}$ is with great pleasure that I introduce this issue of Seminars in Plastic Surgery focused upon facial rejuvenation. This issue is a milestone for us because it is our first written as a joint issue with our colleagues at Facial Plastic Surgery. Rather than focus on the basics, we have chosen to emphasize more complex techniques and technical details of their execution. In this issue, we also include emerging information regarding compartments of the face and relate this to techniques to provide fill volume, an area of increasing interest and focus. We hope that this issue will be of use to plastic surgeons and our never-ending quest for facial rejuvenation.

Larry H. Hollier, Jr., M.D., F.A.C.S. ${ }^{1}$ Guest Editor

${ }^{1}$ Division of Plastic Surgery, Baylor College of Medicine, Texas Children's Hospital, Houston, Texas.

Address for correspondence and reprint requests: Larry $\mathrm{H}$. Hollier, Jr., M.D., F.A.C.S., Professor and Program Director, Division of Plastic Surgery, Baylor College of Medicine, Texas Children's Hospital, 6621 Fannin, MC-CC610.00, Houston, TX 77030 (e-mail: larryh@bcm.edu).
Contemporary Face-lift Techniques; Guest Editor, Larry H. Hollier, Jr., M.D., F.A.C.S

Semin Plast Surg 2009;23:245-246. Copyright (C) 2009 by Thieme Medical Publishers, Inc., 333 Seventh Avenue, New York, NY 10001, USA. Tel: +1(212) 584-4662.

DOI 10.1055/s-0029-1242179. ISSN 1535-2188. 